\title{
Derecho colectivo y comunitarismo como modelos sociales de futuro
}

\section{RESUMEN}

La actual discusión de la public philosophy sobre el comunitarismo, tiene directas implicancias en la interpretación de los derechos colectivos. Los comunitaristas ven la nueva sociedad bajo la tutela de los derechos minoritarios frente a las aspiraciones de un derecho positivo e individual, y que de ese conflicto resulta el futuro modelo de una sociedad pluricultural. El postulado y el nuevo desafío hacia la "buena sociedad" postnacional, es realizar un discurso de la diferencia que ayuda en formular una política de la equivalencia frente a las minorias de acuerdo a sus necesidades coletivas.

\begin{abstract}
The discussion of the public philosophy about comunitarism has direct effects on the interpretation of colective rights. The school of comunitarism interprets the new society by the protection of colective rights facing the aspiration of positive $o$ individual right. New models of pluricultural societies are surging from this permanent conflict. The discourse of difference realizes although the claim than the challenge in view of a postnational good society, helping to create politics of equity which take care of the colective demands of minorities.
\end{abstract}

\section{Introducción}

En el presente artículo se revisará la discusión so-

1 Universidad Academia de Humanismo Cristiano. Email: gensil@netline.cl.

2 La controversia acerca del comunitarismo comenzó con Rawls y su Teoría de la Justicia (Rawls 1971), inicialmente como una discusión al interior de la nueva filosofía moral norteamericana. Sin embargo, rápidamente se extendió a otras cuestiones referidas a la teoría social en un sentido amplio. Desde un punto de vista político, se trata de la disputa entre liberales y comunitaristas por diversas opciones de transformación y reforma social, por concepciones alternativas de ciudadanía y bre derechos colectivos e individuales a partir de nuevos modelos teóricos. El objetivo es analizarlos, a un nivel antropológico-sociológico, como modelos sociales futuros. Varias preguntas conforman las líneas principales de argumentación:

¿Es posible concebir nuevas formas de consolidación social? ¿En qué modelos sociales adquieren mayor relevancia los derechos colectivos de las minorías (por ejemplo, las minorías étnicas), en paralelo a la consideración igualitaria que se da a la heterogeneidad, en las formaciones estatales democráticas? ¿Es la construcción de una sociedad multicultural bajo tutela estatal un medio eficaz para la integración del "otro"?

A nivel de la confrontación entre sociedad y comunidad, la filosofía política norteamericana nos proporciona algunas pistas nuevas. En un primer momento, se analizarán los principales argumentos de los comunitaristas norteamericanos sobre la relación entre sociedad, en el sentido de una comunidad, y primacía del derecho colectivo frente a las aspiraciones jurídicas individuales, desde la óptica de las minorías étnicas y culturales. En un segundo momento se presentará la nueva "sociedad responsable" (Etzioni 1999) como futuro modelo multicultural dentro de las constelaciones postnacionales (Habermas 1998).

Por tanto, el objetivo no es introducirse en la actual discusión sobre el comunitarismo- ${ }^{-}$, sino prestar atención a las ideas centrales de esta reciente área filo-

sociedad civil y democracia participativa; así como también de la tensa relación entre individualismo y bien común, como regulación de la acción humana. Desde un punto de vista analítico-metódico en el debate participan estrategias rivales en teoría social y respecto al lugar social del intelectual como intérprete de la sociedad. Finalmente, desde un punto de vista filosófico-moral, la disputa se refiere a diversas formas de fundamentación y pretensiones de validez de normas y valores. Un resumen de este debate lo ofrece Jaeger (1997). 
sófica en relación a los nuevos procesos sociales. La "anatomía de la buena sociedad" (Etzioni 1991: 50 ), en la forma de un orden voluntario y de limitación de la autonomía individual, es apreciada en las actuales democracias como la finalidad de una nueva forma de individualismo (solidario) y de moral. La política de reconocimiento de las minorías culturales (así como las diversidades específicas de género), tanto dentro como fuera de las fronteras de cada país, se transforma de ese modo en uno de los desafíos centrales de las sociedades nacionales.

Sin embargo, antes de ver esto, debe examinarse la transformación del rol de los intelectuales como mediadores de la sociedad en su conjunto, bajo la pregunta: ¿Cómo ha de ser considerado bajo estas nuevas premisas el rol de los futuros intelectuales $\mathrm{e}$ investigadores?

\section{La Ciencia aplicada en la sociedad civil moder- na}

La teoría social del comunitarismo, en sus implicancias políticas, consuma el cambio desde una filosofía del "individualismo ontológico" (Bellah 1991: 15), que minimiza los procesos de socialización y considera al individuo como la única realidad permanente, hacia una "filosofía social más madura" (Bellah 1991: 22), que considera los procesos comunicativos públicos de la sociedad civil moderna en toda su variedad y amplitud. Dicho cambio proporciona los presupuestos metódicos necesarios para hacer efectivas las implicancias políticas de la teoría social comunitarista. Esta nueva filosofía social (public philosophy) exige la transformación del intelectual moderno en un intelectual social, que debe dar expresión interpretativa a la realidad histórica de su tiempo. Ante una sociedad que no se debe comenzar a construir ahora, sino que ha existido desde siempre como un universo social y moral, su tarea se limita a una interpretación crítica de las estructuras culturales de sentido presentes en el mundo de vida, y a la observación participativa en la comunidad de quienes participan de esa cultura. De este modo, la tarea del intelectual es la de un hermeneuta, involucrado en el sentido común de la sociedad civil y el espacio público de su tiempo, y no la de alguien que desde un puesto superior de observación opera como analista y crítico (Walzer 1992: 78-80).

¿Qué conceptos sigue el principio comunitario al interior de sociedades democráticas consolidadas? ¿Qué principios (jurídicos) se cristalizan a partir de ello? ¿Qué críticas se hacen a esas orientaciones sociales?

\section{Comunitarismo y estado de derecho}

Tönnies (1996) señala que en Norteamérica la discusión ha sido más controvertida que en Europa. El comunitarismo constituye una crítica abierta a los principios del liberalismo, en el sentido que pone en cuestión el imperio de la ley (rule of law) como igualdad abstracta entre las personas, y la delegación de decisiones políticas al Estado. Desde esta óptica postmoderna, la igualdad y la racionalidad no son conceptos universales de toda la humanidad, sino que tienen sólo validez particular para la cultura que los ha creado.

De acuerdo a Walzer (1993: 160), uno de los grandes defensores del comunitarismo norteamericano, Ios comunitaristas piden la entrega de la sustancial "soberanía del individuo" formulada por Hegel. Siguiendo punto a punto los planteamientos del romanticismo, se vuelven contra la imagen abstracta de hombre de la Revolución, contra la abstracción no coloreada por ningún atributo particular como etnicidad o religión y otros; un individuo liberado de sus ataduras, que es el punto de partida para el moderno estado de derecho. Concretamente, Walzer cuestiona...

"(el) autorretrato del individuo liberal, cuya única constitución es su arbitrariedad privada y que, está libre de toda atadura, no conoce valores comunitarios, relaciones estables, costumbres comunes y usos o tradiciones --que se presenta sin ojos, sin dientes, sin gusto, sin nada" (Walzer 1993: 171).

En esta misma dirección va Taylor (1989: 179 y ss) cuando critica al estado de derecho moderno por partir no de grupos de personas solidariamente unidas, sino de individuos que actúan entre sí antagónicamente para hacer prevalecer sus derechos frente a los otros y al Estado. Lo que une a las personas es ignorado y lo que los separa, fomentado.

En el modelo social comunitarista, participación se escribe con mayúscula. El comunitarismo promueve un regreso a los habits of the heart (Honneth 1993: 12) en alusión a la democracia liberal; en cualquier caso, la aplicación radical de ideas 
comunitaristas conduce frecuentemente a resultados contradictorios: a los escritos de Walzer se remiten entretanto los jóvenes derechistas. A diferencia de la izquierda, ellos encuentran en el comunitarismo una base ideológica consistente (Tönnies 1996: 15-16).

Tönnies (1996) critica al mismo tiempo que el comunitarismo está superado por dos razones:

a) El comunitarismo sería la expresión política del movimiento "lo pequeño es hermoso" que, entre 1975 y 1985, fue sostenido como concepto universal en la reflexión sobre autoorganización. De acuerdo a Tönnies (1996: 18), ese piso ya no existe, así "la microvida, el humus, que el enfoque comunitarista presuponen es demasiado escaso".

b) El comunitarismo ya habría pasado su mejor época. Ha quedado ya fuera de lugar oponerse al intervencionismo estatal: el Estado como órgano de acción socioeconómica es prácticamente imperceptible. Tönnies (1996: 18) habla de un quietismo estatal a raíz del "thatcherismo" vigente, es decir, de la capitulación del Estado ante la economía. En la discusión actual, tiene mayor validez exigir que el Estado tenga una mayor conciencia de responsabilidad (social):

“...se debe promover un actuar [del Estado I.G] claro y consciente, que se caracterice no por la cantidad, sino por la calidad. A un Estado así, no inseparablemente entremezclado con la sociedad, sino antagónicamente contrapuesto a ella, que se considere como el guardián del bienestar general, le bastaría con pocas reglas pero claras, y no dejaría que millones de personas jóvenes en condiciones de trabajar vegeten apáticamente a costa de la ayuda social" (1996: 19).

¿Cuáles pueden ser las consecuencias de una política comunitarista para los nacionalistas de derecha y para las minorías culturales?

\section{Igualdad de derechos en vez de igualdad}

En los Estados actuales se trata de definir las relaciones étnicas de los distintos grupos culturales reconocidos, bajo el estandarte de la hegemonía estatal, en el marco de una igualdad de respeto.

Esta igualdad de respeto plantea, según Rex (1996:
15-6), cuatro exigencias a la futura sociedad orientada hacia los grupos:

a) Por una parte, los grupos son definidos como unidad a nivel de la esfera pública estatal y como diferencia a nivel privado y comunal;

b) una sociedad puede ser homogénea a nivel de lo público e aspirar al mismo tiempo a prácticas culturales y comunales;

c) una sociedad debería reconocer a nivel de lo público la heterogeneidad y diferentes derechos para grupos distintos, e igualmente persistir en la diversidad cultural que se da en la práctica entre los distintos grupos; y

d) una sociedad puede ser heterógenea y contener a la vez diversos derechos en el ámbito público, y a pesar de una considerable homogeneidad en las prácticas culturales de los grupos.

Rex considera como el requisito para el desarrollo de una sociedad multicultural, el desarrollo de una sociedad civil, de acuerdo a Weber y Durkheim:

"Así, en el mundo moderno el multiculturalismo involucra, por una parte, la aceptación de una sola cultura y de un solo conjunto de derechos individuales que rigen el dominio público; y por otra, una variedad de culturas folk en los dominios privado, doméstico y comunal" (Rex 1996: 18).

Las instituciones más importantes a nivel de lo público son las instituciones legales, las políticas y las económicas. De ese modo:

a) la ley -- en el sentido de lo ideal en una sociedad multicultural-- debería definir y proteger de igual manera, al interior de la sociedad, los derechos individuales y los colectivos;

b) la esfera de la política debería conceder a todos los miembros de una sociedad multicultural, el derecho de participación política y ejercicio del poder, a través del voto u otros medios;

c) la economía debería remitirse en primera línea a las instituciones de mercado. El mercado debe excluir el uso de la violencia y la competencia; el concepto de caridad: "en la conducta de mercado es la moralidad más abstracta de apegarse a las normas 
del intercambio mercantil pacífico" (Rex 1996: 19). La economía debería orientarse al bienestar (la cohesión interna) de la comunidad.

\section{El discurso de la diferencia}

Dos obstáculos se presentan a las instituciones públicas en los Estados modernos: por un lado, la intervención en la esfera económica de la propiedad, con fines de control y eficiencia productivas, y por otro, la intromisión en los ámbitos familiares y comunales y, a partir de ello, la ampliación de los derechos sociales.

Las comunidades minoritarias --incluyendo los grupos indígenas--, en la medida en que cuestionen el orden vigente, provocan conflictos sociales de clases. Un nuevo orden social de la sociedad multicultural surge así del diálogo y del conflicto cultural entre dichas comunidades (Rex 1996: 29).

Taylor (1993) examina los distintos discursos de demanda de reconocimiento de las minorías nacionales y también, al interior de fronteras nacionales, de las diferencias culturales y de género existentes. Analiza el discurso del reconocimiento tanto en la esfera de las relaciones personales como en la esfera pública, concentrándose finalmente en ésta última. Parte del principio (jurídico-social) de la igualdad de derechos de todos los ciudadanos y hace derivar de él una política de la diferencia. ${ }^{3}$

“...que brota orgánicamente de la política de la dignidad humana universal por medio de uno de esos giros con los que hace tiempo atrás estamos familiarizados, y en ellos una nueva interpretación de la condición social humana imprime un significado radicalmente nuevo a un principio viejo" (Taylor 1993: 62).

El principio de igualdad, en todo caso, es negado por una cultura euro, o bien, etnocéntrica, fortalecida por el liberalismo, que ejerce como instancia cegadora frente a las diferencias (Taylor 1993: 68). El caso de las aspiraciones autonomistas de la provincia canadiense de Quebec muestra cómo es llevada

3 En su comentario al trabajo de Taylor, Gutman (1993) remite a la lucha de los afroamericanos en USA por ser reconocidos.

4 La política de la survivance debe asegurar, de acuerdo a Taylor (1993: 87-88), que también en el futuro habrá un grupo de personas que hará uso efectivo de su posibilidad de utilizar la lengua francesa. Esa política debe ser un esfuerzo activo por a cabo una política cultural activa, en el sentido de la admisión de metas (derechos) colectivas frente a los derechos individuales. Esto puede traer consigo, por una parte, libertad de acción y limitaciones particulares (leyes linguísticas), como también puede llegar a considerarse como discriminatoria en relación a los derechos individuales. ${ }^{4}$ En cualquier caso, una política como ésta se sostiene en el principio de abrir una determinada posibilidad a una población existente.

En el actual liberalismo de derecha aparece una política de la consideración igualitaria. Sin embargo, ésta se muestra clausurada frente a la diferencia, porque:

a) insiste en un aplicación igualitaria de las reglas definidas por el derecho, sin dejar espacio a las excepciones, y

b) se muestra desconfiada ante las metas colectivas.

A ello contrapone Taylor (1993: 90) el "discurso de la diferencia", donde se recoge la aspiración de los distintos grupos a la sobrevivencia y no a la disociación. Tiene una meta colectiva pero, como consecuencia, lleva también a una modificación casi inevitable de las leyes, cuya validez quedaría circunscrita a los diferentes contextos culturales.

Las sociedades antiguas se vuelven al mismo tiempo crecientemente multiculturales y permeables, a través de procesos como la inmigración. En este contexto de cambio social aparecen nuevamente las preguntas por el poder y la arrogancia cultural sobre todo del Occidente (Gellner 1991).

"La exigencia radicaba en permitir que las culturas se defendieran a símismas dentro de unos límites razonables. Pero la otra exigencia siguiente que tratamos aquí es que todos reconozcamos el igual valor de las diferentes culturas, que no sólo las dejemos sobrevivir, sino que reconozcamos su valor" (Taylor 1993: 94-95).

formar a los miembros de ese grupo en el sentido de que se preocupen que también las generaciones futuras se reconozcan como francoparlantes (ver el debate norteamericano sobre el comunitarismo resultante de la ciudadanía y la organización social en Honneth (1993). 
Luego de los procesos estatales de descolonización, hoy se formula claramente una exigencia de reconocimiento: el influyente trabajo de Fanon (1961) muestra el camino de liberación de las imágenes de sí mismo impuestas por los colonizadores. La lucha por la libertad y la igualdad debe incluir la revisión de esas imágenes. Aquí puede ser muy útil la implementación de curricula multiculturales.

Oponer a la política de la igualdad una política de la igualdad de derechos tiene diversas consecuencias. Estas valen en primera línea para la identidad de las personas a raíz de un canon educativo transformado, en el sentido del respeto y no en la forma de una solidaridad sobrepuesta. De acuerdo a Kimball (cit. por Taylor 1993: 105).

“...la opción a la que hoy nos enfrentamos no es entre una cultura occidental 'represiva' y un paraiso multicultural, sino entre cultura y barbarie. La civilización no es un don, es un logro: un logro frágil que necesita ser constantemente expurgado y defendido de sus atacantes de dentro y de fuera".

En síntesis, deben lograrse nuevas formas de convivencia activa con otras culturas --en todo el mundo y al interior de cada sociedad--, de acuerdo a las cuales debe reformularse el valor relativo de cada cultura particular. Para los comunitaristas el punto de partida para una política de igualdad de derechos para las minorías es la indispensable orientación del derecho individual de acuerdo a las necesidades colectivas.

Clavero (1994: 124) adhiere a los postulados de Walzer y Taylor cuando, en relación al derecho de las minorías indígenas, sostiene que el individuo tiene el derecho a una cultura, cuya expresión puede ser de carácter colectivo y que, como consecuencia lógica de ello, ese derecho a una comunidad cultural se pueda transferir a una comunidad cultural como colectivo. Este ejercicio jurídico prepara al mismo tiempo un nuevo nivel de conflicto entre los derechos individuales y los colectivos que, en cualquier caso, se encuentra en la lógica de una interpretación jurídica práctica:

"Todo derecho colectivo, todo orden comunitario, implica desde luego discriminaciones y produce desigualdades, pero no es ésta una evidencia que zanje por sí el asunto. Toda colectividad, toda comunidad, tendrá un test que salvar: respeto a dere- chos particulares y respeto a derechos universales, unos y otros individuales. $Y$ es un test de legitimidad aplicable como ya sabemos a todas ellas, tanto al estado no indígena como a la comunidad indígena. Test no parece que haya otro, que lo haya con base de derechos. Y es, debe ser, test común" (Clavero 1994: 132).

De acuerdo a Habermas (1997: 148-50) se trata --a partir de los trabajos de Taylor-- de las posibilidades de implementar una teoría individualista de la protección legal, para la articulación y mantenimiento de derechos colectivos en las construcciones democráticas. En el centro de los intereses se encuentra el reconocimiento de las identidades colectivas y la igualdad de derechos de las diversas formas culturales de vida, frente a iguales posibilidades de existencia.

\section{Conclusiones}

Los representantes del comunitarismo ven las posibilidades del reconocimiento tanto en una política que considere las diferencias culturales, como en una política que generalice los derechos subjetivos: una debe equilibrar el precio que otra exige al adoptar la forma de un universalismo uniformante. El comunitarismo espera del Estado de Derecho --a partir de una negación de la neutralidad ética-- la promoción activa de determinadas concepciones de calidad de vida.

Habermas (1997: 154) exige, bajo la premisa de una teoría del derecho correctamente comprendida --él hace alusión a la fidelidad a la Constitución--, exactamente una política de reconocimiento que protege la integridad individual también en sus propios contextos identitarios. Critica el modelo opuesto, el comunitarista, en tanto éste corrige desde otros puntos de vista normativos el corte individualista del sistema jurídico, y plantea, en cambio, sólo su realización consecuente.

Habermas ve la lucha de las minorías étnicas y culturales sometidas por el reconocimiento de su identidad colectiva como movimientos de emancipación, cuyo derecho colectivo se define en primer lugar culturalmente, aun cuando están en juego otras formas de dependencia social y económica. Frente a esta lucha contra la herencia eurocentrista, la forma de comprensión de la cultura mayoritaria no puede permanecer intocada. Al mismo tiempo, las reper- 
cusiones sociales son distintas de acuerdo al país y al tipo de minoría (migrantes, minorías étnicas).

"El desafio será mayor cuanto más profundas sean las diferencias religiosas, raciales o étnicas, o los desfases histórico-culturales que deben ser superados; será tanto más doloroso cuanto más las tendencias a autoafirmarse asuman un carácter fundamentalista que tienda a poner límites, ya sea porque la minoria que lucha por su reconocimiento, producto de su experiencia de impotencia, se bate en retirada, o porque, en primer lugar, debe despertar la conciencia a través de la movilización de masas para la articulación de una identidad constructivamente producida" (Habermas 1997: 160).

De este modo, las afirmaciones de los comunitaristas en relación con la "buena sociedad" se pueden analizar en tres niveles:

a) en un debate interno en Norteamérica sobre lo políticamente correcto, que se asemeja a una crítica al "irrenunciable" proyecto de la modernidad y que aporta escasamente al análisis de las luchas por el reconocimiento y sus correspondientes soluciones políticas;

b) en un discurso filosófico sobre la relación entre moral y ética, o en una relación interna entre significación y validez que renueva la antigua pregunta por la posibilidad efectiva de trascender nuestro respectivo contexto linguiístico y cultural, o bien que todos los estándares de racionalidad permanecen aprisionados dentro de determinados conceptos del mundo y tradiciones;

c) en la pregunta por el derecho o los "derechos" de minorías ultrajadas y menospreciadas, que de ese modo adquieren sentido jurídico en referencia a un nivel legal y político.

La sociedad comunitarista, como síntesis de tradición y modernidad, apunta a encontrar un camino que una elementos de la tradición ("basado en un orden virtuoso") con elementos de la modernidad ("la bien protegida autonomía"). Aquí cobra validez, de acuerdo a Etzioni (1999: 19), el encontrar un equilibrio entre los derechos universales individuales y el bienestar común, entre el yo y la comunidad, a lo que le debe seguir la pregunta central acerca de cómo puede ser logrado y mantenido en la práctica un equilibrio como ese. Una política estatal activa del reconocimiento de diferencias culturales, representa un primer paso en dirección a esta transformación social solidaria.

\section{Agradecimientos}

Agradezco al Dr. Haroldo Quinteros, de la Universidad Arturo Prat, su colaboración en la traducción de citas en inglés y alemán.

\section{BIBLIOGRAFIA}

BELLAH, R., 1991. The good society. Knopf, New York.

CLAVERO, B., 1994. Derecho Indigena y Cultura Constitucional en América. Ed. Siglo XXI, México, D.F.

ETZIONI, A., 1999. Die Verantwortungsgesellschaft. Individualismus und Moral in der heutigen Demokratie, Ullstein, Berlín.

FANON, F., 1961. Les damnés de la terre, Maspero, París. (Traducción al español: Los condenados de la tierra. FCE, México, $1^{\mathrm{a}}$ edición en español 1963 ).

GELLNER, E., 1991. Nationalismus und Moderne. Rotbuch Verlag, Berlín.

---- 1999. Nationalismus. Kultur und Macht. Siedler, Berlín.
GUTMAN. A., 1993. Introducción. En El multiculturalismo y la política del reconocimiento, pp. 13-42. EFCE, México, D.F.

HABERMAS、 J., 1997. Anerkennungskämpfe im demokratischen Rechtsstaat. En Multikulturalismus und die Politik der Anerkennung, Ch. Taylor (Ed.) Fischer, Francfort del Meno, pp. 147-196.

---- 1998. Die postnationale Konstellation und die Zukunft der Demokratie. Die postnationale Konstellation. Politische Essays. Suhrkamp, Francfort del Meno, pp. 91-169.

HONNETH, A.(Ed.), 1993. Kommunitarismus. Eine Debatte uber die moralischen Grundlagen moderner Gesellschaften, Campus Verlag, Francfort del Meno.

JAEGER, F., 1997. Gesellschaft und Gemeinschaft. Die Geselischaftstheorie des Kommunitarismus und die 
politische ldeengeschichte der "civil society" in den USA. En Geschichte zwischen Kultur und Gesellschaft, T. Mergel y T. Welskopp (Eds.) pp. 299-322. Beck, Munnich.

RAWLS, J., 1971. A theory of Justice, University of Cambridge, Cambridge.

REX, J., 1996. Ethnic Minorities in the Modern Nation State. Working Papers in the Theory of Multiculturalism and Political Integration, Macmillan Press, Warwick-Londres.

TAYLOR, CH., 1989. The Liberal-Communitarian Debate. En Liberalism and the Moral Life, N. Rosemblum (Ed.), University of Cambridge, Cambridge/ Mass.

1992. Multiculturalism and, the politcs of recognition, Princeton University Press, Princeton, New Jersey.
- 1993. El mulficulturalismo y la política del reconocimiento. FCE, México, D.F.

TÖNNIES, S., 1996. Kommunitarismus - dieseits und jenseits des Ozeans. En Aus Politik und Zeitgeschichte, Tomo 36, $\mathrm{N}^{\circ} 30$, Agosto, Trier, págs. 13-21.

WALZER, M., 1992. Sphären der Gleichheit. Ein Plädoyer für Pluralitat und Gleichheit, Campus Verlag, Francfort del Meno.

--1993. Krilik und Gemeinsinn. Drei Wege der Gesellschaftskritik, Francfort del Meno, Fischer. 


\section{Normas Editoriales para la Revista \\ Estudios Atacameños}

\section{Generalidades}

1. Enviar el manuscrito en disquete, escrito en programa Word, y una copia impresa en papel a nombre de:

Hans Gundermann

Editor General de Estudios Atacameños

Instituto de Investigaciones Arqueológicas y

Museo R. P. Gustavo Le Paige S. J.

(IIAM), Universidad Católica del Norte

Correo San Pedro de Atacama

II Región - CHILE

Email: museospa@tie.cl

2. El texto deberá estar escrito en letra Times New Roman tamaño 12.

3. El escrito, considerando todas las secciones e incluyendo bibliografía y anexos, no deberá sobrepasar las 35 páginas tamaño carta, a espacio simple.

4. Es responsabilidad de los autores atenerse a estas normas, pulir la redacción y revisar la ortografía.

\section{Normas Básicas}

\section{Secciones del manuscrito:}

Resumen en español (5 a 10 líneas)

Abstract en inglés (5 a 10 líneas)

Palabras claves

Texto

Agradecimientos

Anexos

Bibliografía

2. Título del trabajo: letra Times New Roman tamaño 18 , minúscula, centrado.

3. Autores: el nombre o nombre deberá(n) alinearse en el margen derecho. Deberá indicarse: institución, dirección postal o dirección electrónica, las que deberán ir al pie de página, consignadas como notas numeradas.
4. Texto: podrá desarrollarse en segmentos que, según la inclusión de unos en otros, irán designados con títulos primarios, secundarios y terciarios.

Los títulos primarios deberán ser escritos en letra minúscula, negrita, alineados a la izquierda.

Los títulos secundarios deberán ser escritos en letra minúscula, normal y alineados a la izquierda.

Los títulos terciarios deberán ubicarse al inicio del párrafo correspondiente, en letra cursiva y separados del texto por un punto seguido.

Los títulos de Resumen y Abstract deberán ir en mayúsculas y en negrita.

Los párrafos no deberán tener sangría.

5. Notas al pie de página: todas las notas deberán ir al pie de página y numeradas correlativamente en números arábicos $(1,2,3 \ldots)$ en superficie, continuando la secuencia iniciada por los datos de autores.

6. Tablas y Gráficos: todas las tablas y gráficos deberán ser numerados en el orden en que son mencionados en el texto. Se deberá proveer un título corto para cada tabla y gráfico, en letra minúscula, negrita, alineado a la izquierda.

7. Figuras (fotografias, mapas, dibujos): deberán ser numeradas secuencialmente, en el mismo orden en que son citadas en el texto y deberán ceñirse a las mismas especificaciones que las Tablas y Gráficos.

8. Bibliografia: los datos de las referencias citadas deberán ser dispuestos en el siguiente orden: autor(es), año, título, imprenta, lugar de publicación. Los autores deberán ir en mayúscula. Sólo la primera letra del título deberá ir en mayúscula. El título de revista, libro o 
monografía deberá aparecer en cursiva. Se deberá consignar solamente las iniciales de los nombres de los autores; cuando haya más de un autor, solamente para el primero deberá aparecer el apellido antes que el nombre. Todos los artículos de revista deben llevar el número de páginas.

\section{Cita de libro:}

HAMPTON, D. R., C. E. SUMMER y R. A. WEBER, 1978. Organizational behavior and the practice of management. Scott Foresman (Ed.), Glenview, Illinois.

\section{Cita de revista:}

MUNIZAGA J., 1974. Deformación craneal y momificación en Chile. Anales de Antropología 11: 329-336.

\section{Cita de artículo en un libro:}

NICHOLS, D. I., 1987. Prehispanic irrigation at Teotihuacán, new evidence: The Tiajinga canals. En Teotihuacán: Nuevos datos, nuevos síntesis, nuevos problemas, E. McClung de Tapia y E. C. Rattray (Eds.), pp. 133-160. Universidad Autónoma de México, México.

Cita de artículo en un volumen de una serie: KHOL, P. L. 1987. The use and abuse of world systems theory: The case of the Pristine West Asian State. En Advances of archaeological method and theory, vol. 11, M. Schiffer (Ed.), pp. 1-35. Academic Press, San Diego. 